\title{
Programs Shape Up for Series of 1988 Materials Conferences in Japan
}

Late May 1988 marks the beginning of three weeks of conferences in Japan focusing on major areas of advanced materials characterization, preparation, and processing. See the following for details on topics, abstract submission, and registration for each of these events. Contact the individual meeting organizers for further information.

\section{MRS International Meeting on Advanced Materials}

This first multi-symposium MRS international meeting, May 30-June 3, Tokyo, to be held outside the United States features 20 technical symposia plus a tutorial symposium on Frontiers in Materials Science and Engineering. Because of the recent addition of five topical symposia, the abstract deadline for the meeting has been extended to December 10, 1987. Symposium topics and organizers are:

A. Composites - S. Umekawa, S. Kimura, and A. Kobayashi

B. Rapid Quenching-T. Masumoto, A. Inoue, and $T$. Suzuki

C. Powder Preparation-K. Akashi and Y. Ozaki

D. Superconductivity -K. Tachikawa and K. Kitazawa

E. Superplasticity - F. Wakai and M. Kobayashi

F. Joining of Metals and CeramicsN. Iwamoto and T. Suga

G. Corrosion/Coating of Advanced Materials - Y. Saito, K. Nii, and M. Yoshimura

H. Shape Memory Materials - K. Shimizu and K. Otsuka

I. Hydrogen Absorbing Materials Y. Sasaki, S. Ono, and S. Suda

J. Structural Ceramics for Mechanical Components - O. Kamigaito and Y. Hamano

K. Multilayers - T. Ohno and R. Yamamoto

L. Microstructure-Property Relationships in Magnetic Materials - $M$. Homma and $Y$. Imaoka

M. Fracture Mechanics-M. Sakai and T. Kishi

N. Biomaterials - I. Miura, H. Aoki, and Y. Imai

O. Catalytic Materials - Y. Moro-oka

$P$. Ionic Polymers-S. Ise and E. Tsuchida

Q. Ordered Polymers - M. Matsuda and $S$. Inoue

R. Photoresponsive Materials - S. Tazuke

S. Advanced Cements and Chemically
Bonded Ceramics - S. Sōmiya, M. Daimon, G. Sudo, and K. Takemoto

T. Biosensers - I. Karube

$X$. Frontiers in Materials Science and Engineering (invited papers only) - R. Roy, M. Doyama, and S. Sōmiya

Advance registration fees are:

30,000 yen - overseas registrants and those from Japan affiliated with a university or public institution

100,000 yen - representatives from private enterprises in Japan

15,000 yen - students

20,000 yen - one-day registration

Fees after March 31, 1988 will be 10,000 yen higher.

Send registrations to: Profs. M. Doyama and S. Sōmiya, MRS International Meeting on Advanced Materials, c/o Nikkan Kogyo Shimbun Ltd., Planning Bureau, 8-10 Kudan Kita, 1-chome, Chiyoda-ku, Tokyo 102, Japan

The meeting is being held the week following the High Technology Exhibition '88 in Tokyo, organized by Nikkan Kogyo Shimbun.

\section{Sixth International Conference on Ion Beam Modification of Materials (IBMM'88)}

This international meeting, cosponsored by the Materials Research Society, Japan Society of Applied Physics, and Okochi Memorial Foundation, will be held June 1217 at Shigaku-Kaikan Hall, Tokyo. This sixth conference in this series will bring together investigators in the field of materials modification by ion beams to discuss recent progress and future trends. Abstracts are sought by January 10, 1988 on the following topics:

Ion beam-solid interaction: ion-beaminduced physical and chemical effects, ion penetration, channeling effect, stopping power, sputtering, damage, radiation effect, beam analysis.

Ion beam mixing: interface modification, recoil implantation, silicide formation, metastable alloy formation, ceramics coating, enhanced adhesion.

Ion beam modification of metals: characterization of implanted layers, surface modification, metastable alloy formation, ion implantation in superconductors.

Ion beam modification of insulators: characterization of implanted layers, physical and chemical properties, modification of polymers, magnetic materials, and ceramics.
Ion implantation in semiconductors: characterization of implanted layers, dose rate effects, beam annealing, buried insulator structure formation, implantation in superlattice structure, amorphous layer formation and crystalline regrowth, device applications.

Novel techniques for materials modification: surface modification by ion-beamassisted process such as reactive etching and deposition, ion beam lithography, focused ion beam process, rapid thermal annealing, shallow junction formation, high and low energy implant.

The conference is chaired by S. Namba (Osaka University) and co-chaired by $\mathrm{N}$. Itoh (Nagoya University), M. Iwaki (RIKEN), J. Kawamoto (Toyota Central Research and Development Laboratories), and T. Takagi (Kyoto University).

The registration fee of 40,000 yen includes a copy of the conference proceedings.

Send abstracts and registrations to: Dr. Kenjo Gamo, IBMM'88 Secretary, Department of Electrical Engineering, Osaka University, Toyonaka, Osaka 560, Japan.

This conference follows the 7th International Conference on Ion Implantation, being held in Kyoto, June 7-10, and runs concurrently with the JSAP-MRS Conference on Electronic Materials.

\section{JSAP-MRS Conference on Electronic Materials}

This conference, sponsored by the Japan Society of Applied Physics and the Materials Research Society, in cooperation with the European Materials Research Society, will be held concurrently with IBMM'88 at Shigaku-Kaikan Hall, Tokyo, from June 1315. Organized by co-chairs Takuo Sugano (University of Tokyo) and R.P.H. Chang (Northwestern University), the conference focuses on "New Materials and New Physical Phenomena for Electronics in the 21st Century." The Program Committee is directed by Kiroshi Kamimura, chairman (University of Tokyo) and Izuo Hayashi, vice chairman (OTR Laboratory). The abstract deadline is February 20, 1988. The registration fee is 30,000 yen until May 15, 1988. After May 15, the registration fee is 35,000 yen.

Send abstracts and registrations to: Prof. Takeshi Kamiya, ICEM'88 Steering Committee, Department of Electronic Engineering, University of Tokyo, 7-3-1 Hongo, Bunkyo-ku, Tokyo 113, Japan. 